\title{
Modeling of Power Losses Caused by Hidden Tree- related High Impedance Faults
}

\author{
A. E. Ashrafi' ${ }^{1}$, A. H. Lotfi ${ }^{2}$, N. Bahador ${ }^{\star 3}$, S. Chatrazar ${ }^{4}$ \\ 1,2,4Electricity Distribution Company of Hamedan Hamadan Province, Hamedan, Mahdiyeh St, Iran \\ ${ }^{3}$ Lorestan University Lorestan, Khoramabad, Iran \\ *Corresponding author, e-mail: hdc_dqm@yahoo.com¹, lotfi_ah@yahoo.com², nu.bahador@yahoo.com³ \\ chatrazarsaeed@yahoo.com ${ }^{4}$
}

\begin{abstract}
The great majority of overhead distribution systems in urban and rural areas of countries such as Australia, Iran and etc., are in interfering with vegetation. This phenomena leads to high impedance faults (HIFs) which not produce enough fault current to be detectable and consequently causes electrical energy losses. In this paper, according to experimental data obtained from measurements, the effective factors in power losses caused by trees are studied and a new numerical model of power loss is presented so as to reflect the effects of environmental conditions and biological classification. The base of this method is according to Samuelson theory. In proposed algorithm, the impacts of species, short-term environmental conditions (temperature and humidity) and long-term environmental conditions (Seasonal variations in physiology) on the power loss estimation are fully considered. Experimental investigations on a real low voltage $(380 \mathrm{~V})$ and medium voltage $(20 \mathrm{kV})$ distribution network verify the algorithm's operation.
\end{abstract}

Keywords: vegetation-related power loss, high impedance faults (HIFs), distribution system, finite element method, experimental investigations.

\section{Introduction}

The importance of precise and low time-consuming evaluation of the power losses in systems is becoming increasingly essential to achieve systems with higher efficiency and reliability. A notable part of power losses in distribution systems is related to the growth of vegetation beside power lines. This tree overgrowth near power lines leads to high impedance faults. These faults cannot provide enough current for protective devices. So undetectability and continuity of them causes large energy loss. However, no accurate method for estimation of these losses has been presented thus far. Previous researches in the field of high impedance fault (HIF) have not considered power loss and just focused on detection and location of HIF on medium voltage [1-4]. As shown in Table 1, the results of two different researches in HIF current measurement are also incompatible with each other. This shows that tree-related power loss is a variable parameter which depends on different factors. Therefore, due to importance of power losses issue in distribution networks, using the results of precise measurement and accurate estimation of losses considering all effective factors can provide solutions for future decisions.

Table 1. Current Drawn by Pine Tree in Contact with $20 \mathrm{kV}$ Conductor $[5,6]$
\begin{tabular}{ccc} 
Species $20 \mathrm{kV}$ power line \\
\hline Pine & $100 \mathrm{~mA}$ & $0.9-2.2 \mathrm{~mA}$ \\
\hline
\end{tabular}

A number of approximation approaches for estimating power losses have been presented in the literature. Numerous studies in the field of numerical estimation of power losses have been done. This kind of estimation was mostly performed for devices with complex geometries. For instance, according to a research work in 2016, due to complex cable's geometry, ac losses prediction of them can only be achieved by advanced numerical tools. That study used finite-element-based models to compute the ac losses of Roebel cables. Another research work which conducted in 2015, described a numerical approach to determine the magnetic power losses caused by alternating magnetizations in thin electrical steel sheets. A 
study in 2016 also presented 3-D numerical modeling of ac losses in multi filamentary MgB2 cables. The important thing in these approaches is to consider the factors affecting leakage current and consequently power losses. In a research work was conducted in 2006, the leakage current analysis was performed on $20 \mathrm{kV}$ suspension porcelain insulator contaminated by salt moisture. This research showed how the both salty moisture affect the insulator performance and for the long-term the flashover could happened and will leads to a phase to the ground fault. Another research in 2002, studied the resistive leakage current characteristic of MOV surge arresters. In this work, different factors including inner moisture were investigated. A research also investigated the effect of moisture on leakage currents of GRP composite hollow cylinders. The experiments showed a direct correlation between the absorbed moisture and the amount of leakage current. Another study investigated the effect of moisture content on leakage current flow through wooden pole structures. A research work conducted in 2013 presented an approach for determination of moisture in paper insulation of power transformers. In a study in 2014, the temperature distribution and moisture content of an SF-insulated CT was studied by considering current flowing through it [8]. In 1988, the effect of temperature field and moisture content in the vicinity of underground power cables which affect current carrying capacity of buried cables was modeled. In addition to environmental factors, material or species should also be considered in modeling. For instance, according to a study in 2012, electric current flowing through trees changed with the species.

Based on measurements taken on the trees touching LV power lines [9], the internal structure of trees and consequently the amount of leakage current passes through them changes in short-term environmental conditions (temperature and humidity) and long-term environmental conditions (seasonal variation in tree physiology). Furthermore, the effect of moisture content variations on electrical resistance is not the same for all species [27]. Considering the factors mentioned above, this research presents a finite element-based algorithm for vegetation-related power loss estimation.

\section{Impressibility of Power Losses from Biological Classification}

In order to verify the impressibility of power losses from biological classification, several HIF experiments were performed on different species of trees under $20 \mathrm{kV}$ power lines in Hamedan/Iran as show in Figure 1. These species included Ash, Poplar and Walnut. The fault's current waveform of each species was captured by using a power analyzer that provides a high sampling rate of 1024 samples/period. Stored data were down loaded by laptop.

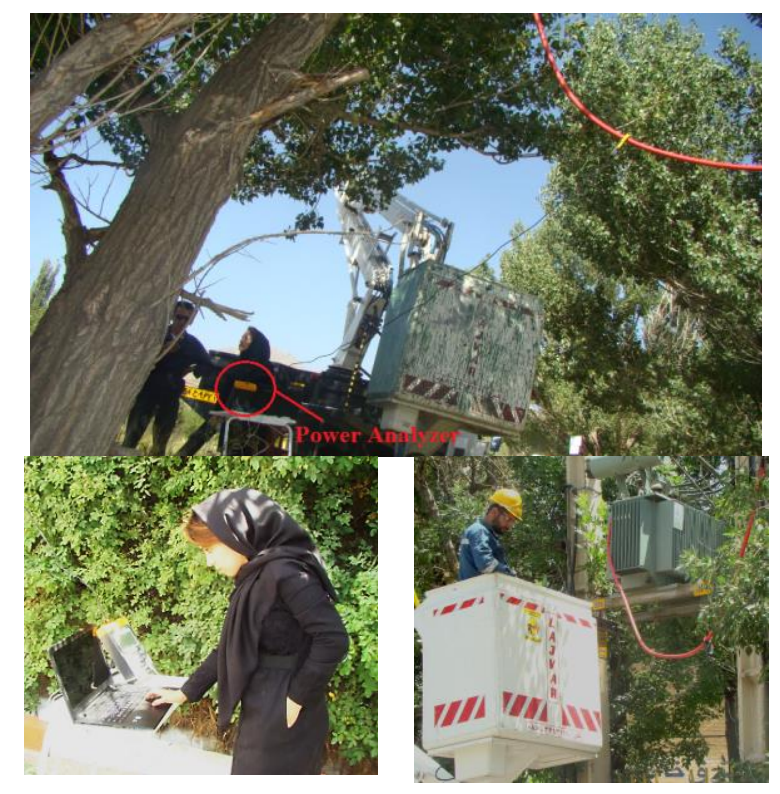

Figure 1. HIF experiments on different species under $20 \mathrm{kV}$ power lines 
The obtained results from tree-related HIF tests of different species on MV power lines are documented in Figures 2. As shown, under similar environmental conditions, measured fault current values are not same for different species.

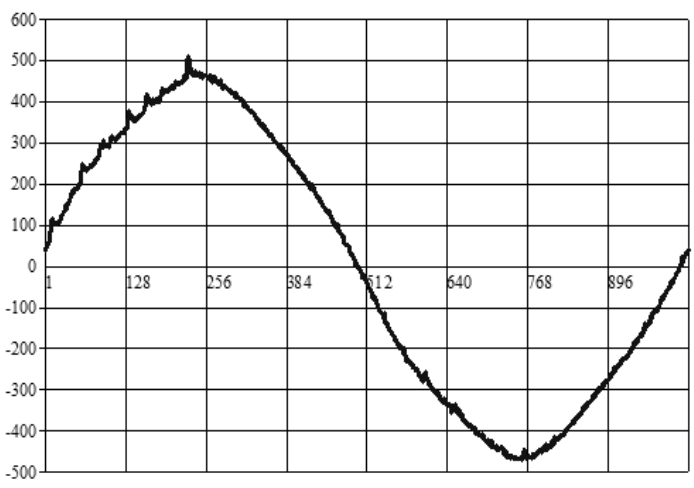

(a)Walnut tree

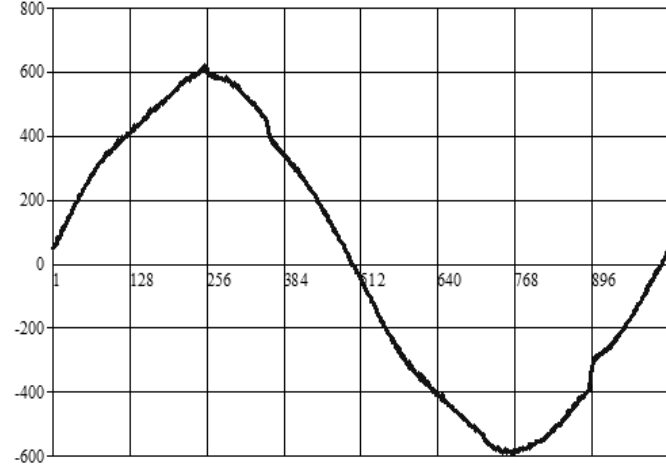

(b)Poplar tree

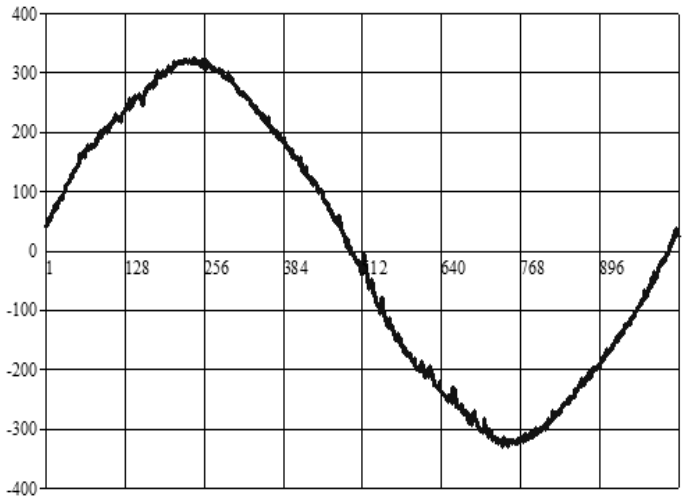

(c)Ash tree

Figure 2. Fault's current waveform of tested species (mA)

\section{Impressibility of Power Losses from Seasonal Variations in Physiology}

A series of experiments were carried out in different seasons (spring, summer and autumn) to verify the hypothesis of losses impressionability from the seasonal variations in physiology. The experiments were conducted on-site on live trees grown next to the 380 volt distribution network in Hamendan, Iran. The tested species included Pine, Ash, Plane and Acacia. Figure shows the tested pine tree. Testing Procedure was as follow: Short piece of cooper conductor had touched the power line and providing connection to tree as show in Figure 3. As minimum leakage current was in the 100 nanometer regime, to accurately measure the total leakage flowing to the intended connection, a micrometer measurement device with accuracy of $0.1 \mu \mathrm{A}$ (Model VC97) had been placed in series with conductor. The variations of leakage current value were studied in different weather and seasonal conditions and summarized in Figures 4 to 7.

Broad-leaf trees in terms of vessels are divided into three classes, semi-ring porous species, diffuse porous species and ring porous species. The wood of ring porous species are divided into two categories, spring wood (early wood) with wider vascular channel and thinner vascular wall which formed during spring season, and autumn wood (or late wood) with narrow vascular channel and thicker vascular wall which formed during autumn season. So ring porous trees do not have the same vascular sections during spring and autumn. While there is no 
significant difference between vascular sections in diffuse porous trees during spring and autumn. Among tested trees, Plane places in diffuse porous group and that is why its vascular sections in spring, summer and autumn are same. So maximum transferred water in its vessels is same in all seasons. According to this point and with regard to this fact that autumn is the most humid season in Hamadan, it can be concluded that the maximum and minimum leakage current of Plane is occurred in autumn and summer respectively. Unlike the Plane, the transferred water in vessels of Ash and Acacia which placed in ring porous species and consequently their leakage current are maximum and minimum in spring and autumn respectively. In conifers such as Pine, there is no considerable difference between tracheids of spring wood and autumn wood [27]. So, changes in maximum leakage current follow the same pattern of Plane. Test results in figures confirm the above assumptions.

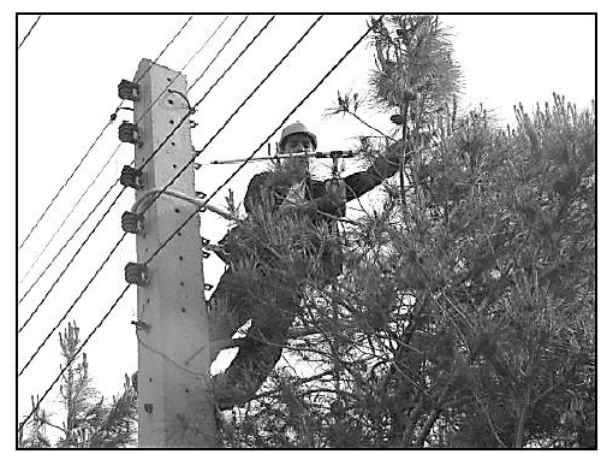

Figure 3. Limb's direct connection to S-Phase of 380 Volt network (Pine-Test)

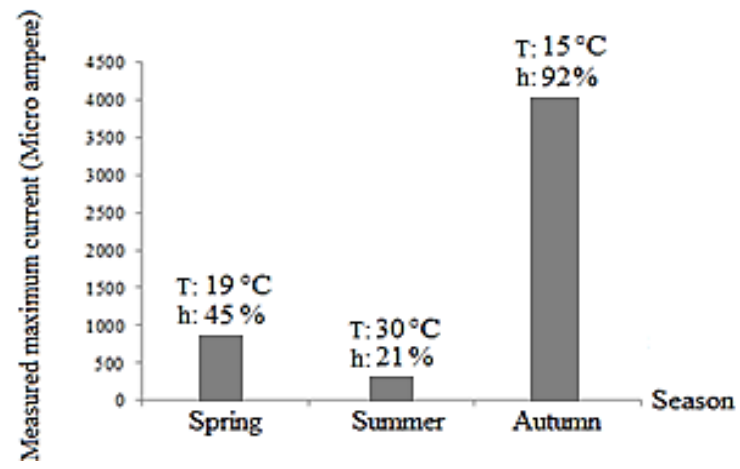

Figure 4. Maximum value of measured leakage current in tested Pine over seasons

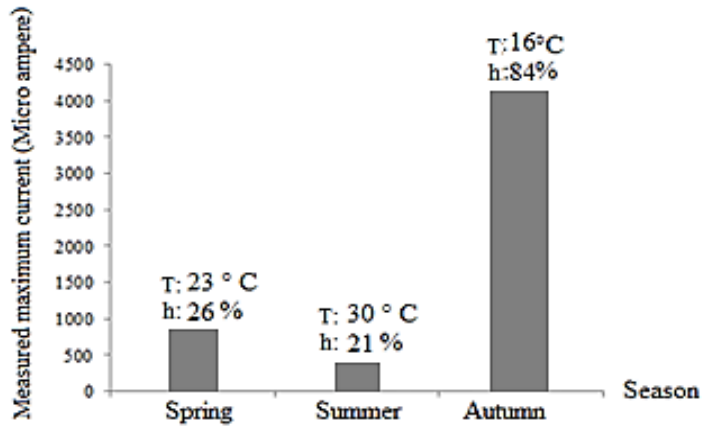

Figure 5. Maximum value of measured leakage current in tested Plane over seasons 


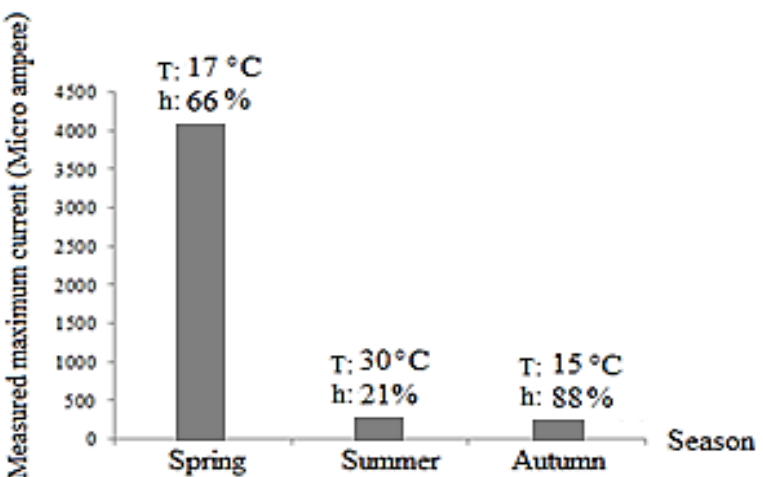

Figure 6. Maximum value of measured leakage current in tested Acacia over seasons

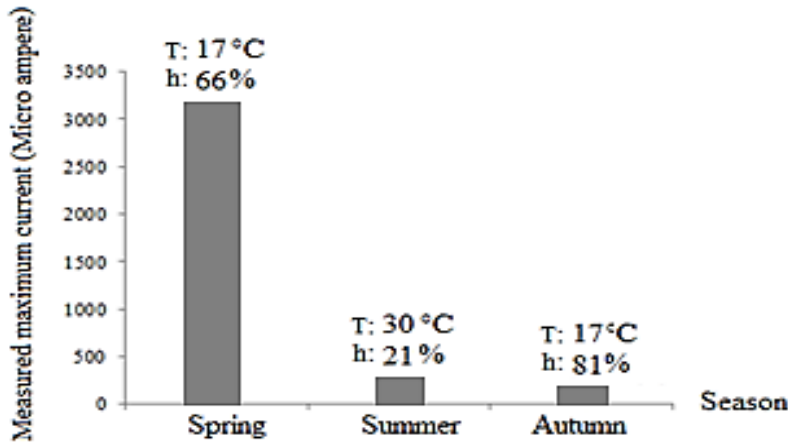

Figure 7. Maximum value of measured leakage current in tested Ash over seasons

\section{Quivalent Moisture Content}

Placing a tree in an environment, results in moisture exchange between air and tree. The values for the equivalent moisture content of wood under various combinations of relative humidity and temperature is shown in Table 2. According to this table, tree moisture content is a function of temperature and humidity. These values are applicable for all species.

To apply moisture content values of Table 1 to proposed algorithm, these values are calculated using the following formula [11].

$$
M C=\frac{1800}{W}\left[\frac{k h}{1-k h}+\frac{k_{1} k h+2 k_{1} k_{2} k^{2} h^{2}}{1+k_{1} k h+k_{1} k_{2} k^{2} h^{2}}\right]
$$

Where, $\mathrm{MC}$ and $\mathrm{h}$ is respectively moisture content (\%) and relative humidity $(\% / 100)$. For the temperature in degrees Celsius $\left(T_{c}\right)$, Values of $W, k, k_{1}$ and $k_{2}$ in equation (1) are also obtained using the following relations.

$$
\begin{aligned}
& W=349+1.29 T_{c}+0.0135 T_{c}{ }^{2} \\
& k=0.805+0.000736 T_{c}-0.00000273 T_{c}{ }^{2} \\
& k_{1}=6.27-0.00938 T_{c}-0.000303 T_{c}{ }^{2} \\
& k_{2}=1.91+0.0407 T_{c}-0.000293 T_{c}{ }^{2}
\end{aligned}
$$


Table 2. Tree Moisture Content [10]

\begin{tabular}{|c|c|c|c|c|c|c|c|c|c|c|c|c|c|c|c|c|c|c|c|c|}
\hline \multicolumn{2}{|c|}{ Temperature } & \multicolumn{19}{|c|}{ Moisture content (\%) at various relative humidity values } \\
\hline$\left({ }^{\circ} \mathrm{C}\right.$ & $\left.\left({ }^{\circ} \mathrm{F}\right)\right)$ & $5 \%$ & $10 \%$ & $15 \%$ & $20 \%$ & $25 \%$ & $30 \%$ & $35 \%$ & $40 \%$ & $45 \%$ & $50 \%$ & $55 \%$ & $60 \%$ & $65 \%$ & $70 \%$ & $75 \%$ & $80 \%$ & $85 \%$ & $90 \%$ & $95 \%$ \\
\hline-1.1 & (30) & 1.4 & 26 & 3.7 & 4.6 & 55 & 63 & 7.1 & 7.9 & 8.7 & 9.5 & 10.4 & 113 & 124 & 13.5 & 14.9 & 16.5 & 18.5 & 21.0 & 243 \\
\hline 44 & (40) & 1.4 & 26 & 3.7 & 4.6 & 55 & 63 & 7.1 & 7.9 & 8.7 & 9.5 & 10.4 & 113 & 123 & 13.5 & 14.9 & 16.5 & 18.5 & 21.0 & 243 \\
\hline 100 & (50) & 1.4 & 26 & 3.6 & 4.6 & 55 & 63 & 7.1 & 7.9 & 8.7 & 9.5 & 10.3 & 112 & 123 & 13.4 & 14.8 & 16.4 & 18.4 & 20.9 & 243 \\
\hline 156 & (60) & 13 & 2.5 & 3.6 & 4.6 & 54 & 62 & 70 & 7.8 & 8.6 & 9.4 & 10.2 & 11.1 & 12.1 & 13.3 & 14.6 & 162 & 18.2 & 20.7 & 24.1 \\
\hline 21.1 & (70) & 13 & 2.5 & 3.5 & 4.5 & 54 & 62 & 69 & 7.7 & 8.5 & 92 & 10.1 & 110 & 120 & 13.1 & 14.4 & 16.0 & 17.9 & 20.5 & 239 \\
\hline 26.7 & (80) & 13 & 2.4 & 3.5 & 4.4 & 53 & 6.1 & 68 & 7.6 & 8.3 & 9.1 & 99 & 108 & 11.7 & 12.9 & 14.2 & 15.7 & 17.7 & 20.2 & 23.6 \\
\hline 322 & (90) & 12 & 2.3 & 3.4 & 4.3 & 51 & 59 & 6.7 & 7.4 & 8.1 & 8.9 & 9.7 & 105 & 115 & 126 & 13.9 & 15.4 & 17.3 & 19.8 & 233 \\
\hline 378 & $(100)$ & 12 & 23 & 3.3 & 42 & 50 & 58 & 65 & 72 & 7.9 & 8.7 & 95 & 103 & 112 & 12.3 & 13.6 & 15.1 & 17.0 & 19.5 & 229 \\
\hline 433 & (110) & 1.1 & 22 & 32 & 4.0 & 49 & 56 & 63 & 7.0 & 7.7 & 8.4 & 92 & 100 & 110 & 12.0 & 132 & 14.7 & 16.6 & 19.1 & 224 \\
\hline 489 & (120) & 1.1 & 21 & 3.0 & 3.9 & 4.7 & 5.4 & 6.1 & 6.8 & 7.5 & 82 & 89 & 9.7 & 106 & 11.7 & 12.9 & 14.4 & 162 & 18.6 & 22.0 \\
\hline 54.4 & $(130)$ & 10 & 2.0 & 2.9 & 3.7 & 45 & 52 & 59 & 6.6 & 72 & 7.9 & 87 & 9.4 & 103 & 11.3 & 12.5 & 140 & 15.8 & 18.2 & 21.5 \\
\hline 600 & (140) & 09 & 1.9 & 28 & 3.6 & 43 & 50 & 5.7 & 6.3 & 7.0 & 7.7 & 8.4 & 9.1 & 10.0 & 11.0 & 12.1 & 136 & 15.3 & 17.7 & 21.0 \\
\hline 656 & (150) & 09 & 1.8 & 2.6 & 3.4 & 4.1 & 48 & 55 & 6.1 & 6.7 & 7.4 & 8.1 & 88 & 9.7 & 106 & 11.8 & 13.1 & 14.9 & 172 & 20.4 \\
\hline 71.1 & (160) & 08 & 1.6 & 2.4 & 32 & 39 & 46 & 52 & 5.8 & 6.4 & 7.1 & 78 & 85 & 9.3 & 103 & 11.4 & 12.7 & 14.4 & 16.7 & 19.9 \\
\hline 76.7 & $(170)$ & 0.7 & 1.5 & 2.3 & 3.0 & 3.7 & 43 & 49 & 5.6 & 62 & 6.8 & 7.4 & 82 & 9.0 & 9.9 & 11.0 & 123 & 140 & 162 & 19.3 \\
\hline 822 & (180) & 0.7 & 1.4 & 21 & 28 & 35 & 4.1 & 4.7 & 5.3 & 5.9 & 6.5 & 7.1 & 78 & 8.6 & 9.5 & 10.5 & 118 & 135 & 15.7 & 18.7 \\
\hline 878 & (190) & 0.6 & 1.3 & 1.9 & 26 & 32 & 38 & 4.4 & 5.0 & 5.5 & 6.1 & 68 & 75 & 82 & 9.1 & 10.1 & 11.4 & 130 & 15.1 & 18.1 \\
\hline 933 & $(200)$ & 05 & 1.1 & 1.7 & 24 & 30 & 35 & 4.1 & 4.6 & 52 & 5.8 & 6 & 7.1 & 7.8 & 8.7 & 9.7 & 109 & 125 & 14.6 & 17.5 \\
\hline 989 & (210) & 0.5 & 1.0 & 1.6 & 21 & 27 & 32 & 38 & 4.3 & 4.9 & 5.4 & 60 & 6.7 & 7.4 & 8.3 & 92 & 10.4 & 120 & 14.0 & 16.9 \\
\hline 1044 & (220) & 0.4 & 0.9 & 1.4 & 1.9 & 24 & 29 & 3.4 & 3.9 & 4.5 & 5.0 & 5.6 & 63 & 7.0 & 7.8 & 8.8 & 9.9 & & & \\
\hline 1100 & (230) & 03 & 0.8 & 12 & 1.6 & 2.1 & 26 & 3.1 & 3.6 & 4.2 & 4.7 & 53 & 60 & 6.7 & & & & & & \\
\hline 1156 & (240) & 03 & 0.6 & 0.9 & 1.3 & 17 & 2.1 & 26 & 3.1 & 3.5 & 4.1 & 46 & & & & & & & & \\
\hline 121.1 & $(250)$ & 02 & 0.4 & 0.7 & 1.0 & 13 & 1.7 & 2.1 & 2.5 & 2.9 & & & & & & & & & & \\
\hline 126.7 & $(260)$ & 02 & 0.3 & 0.5 & 0.7 & 09 & 1.1 & 1.4 & & & & & & & & & & & & \\
\hline 1322 & (270) & 0.1 & 0.1 & 0.2 & 0.3 & 0.4 & 0.4 & & & & & & & & & & & & & \\
\hline
\end{tabular}

\section{The Electrical Resistance of Different Trees}

The electrical resistance of trees is affected by several factors, including tree species, temperature and humidity of environment [9]. Therefore, each species has its own electrical characteristics. Figure 8 shows electrical resistance-moisture content characteristics of the sample trees, including pine, spruce, beech, birch, larch and oak.

There have been many studies of this type, in which the linear relationship between the logarithm of electrical resistance of tree with its moisture content is extracted.

Logarithmic model used in this paper, is Samuelson model proposed in 1990 that shows the relation between electrical resistance (in mega ohms) with moisture content (in percentage terms) with the following equation.

$$
\log [\log (R)+1]=a \cdot h+b
$$

Where $R$ is the electrical resistance of tree in terms of mega-ohms, $a$ and $b$ are coefficients of the model.

Equation (3) has been proved to be in conformity with experimental data and extensively used in studies of other researchers. Furthermore, the values of coefficients $a$ and $b$ are precisely obtained for different species in numerous studies. For instance, the values of these coefficients for some trees are listed in Table 3.

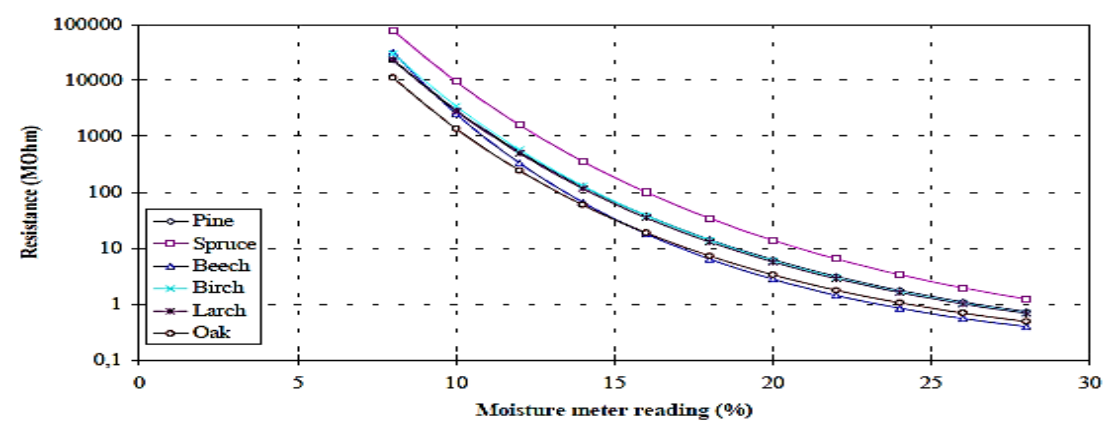

Figure 8. Electrical resistance-moisture content characteristics of some tree species [12]

Bulletin of EEI Vol. 5, No. 4, December 2016: $390-402$ 


\section{Electrical Resistance of Softwood and Heartwood of Trees}

The internal structure of wood does not have a significant impact on the values of the electrical resistance of the tree. The electrical resistance of the softwood and heartwood of pine measured by theses researchers is shown in Figure 9.

Figure 9 shows the correlation between electrical resistance values of sapwood and heartwood. According to these results, difference in moisture content for the same electrical resistance is only 0.5 percent (Table 4). Indeed, at high moisture contents, there is no significant difference between the electrical resistance of sapwood and heartwood. The difference would be notable at low moisture contents. For instance, electrical resistance of the heartwood is two times larger than sapwood at the moisture content of $8 \%$.

Table 3. Regression Coefficients (Samuelsson model) [13]

\begin{tabular}{|c|c|c|c|c|}
\hline \multirow{2}{*}{ Species } & \multirow{2}{*}{$\begin{array}{c}\mathrm{N}^{\circ} \\
\text { samples }\end{array}$} & \multicolumn{3}{|c|}{ Parallel to the grain (Rp) } \\
\hline & & $\mathbf{a}$ & $\mathbf{b}$ & $\mathbf{R}^{2}$ \\
\hline $\begin{array}{l}\text { Beech } \\
\text { Fagus sylvatica }\end{array}$ & 36 & $-0.046722 \pm 0.000579$ & $1.12606 \pm 0.008708$ & 0.994 \\
\hline $\begin{array}{l}\text { European white oak } \\
\text { Quercus robur }\end{array}$ & 36 & $-0.046368 \pm 0.000597$ & $1.07042 \pm 0.007946$ & 0.994 \\
\hline $\begin{array}{l}\text { American red oak } \\
\text { Quercus rubra }\end{array}$ & 36 & $-0.045562 \pm 0.000508$ & $1.11785 \pm 0.006794$ & 0.995 \\
\hline $\begin{array}{l}\text { American white oak } \\
\text { Quercus alba }\end{array}$ & 36 & $-0.0514145 \pm 0.000899$ & $1.16365 \pm 0.011588$ & 0.989 \\
\hline $\begin{array}{l}\text { American ash } \\
\text { Fraxinus sp. }\end{array}$ & 36 & $-0.051567 \pm 0.000621$ & $1.13545 \pm 0.009242$ & 0.995 \\
\hline $\begin{array}{l}\text { American chestnut } \\
\text { Castanea dentata }\end{array}$ & 36 & $-0.0393465 \pm 0.000775$ & $1.0294 \pm 0.011427$ & 0.987 \\
\hline $\begin{array}{l}\text { Iroko/African teak } \\
\text { Chlorophora excelsa }\end{array}$ & 36 & $-0.07511565 \pm 0.001854$ & $1.33626 \pm 0.022151$ & 0.979 \\
\hline $\begin{array}{l}\text { American cherry } \\
\text { Prumus serotina }\end{array}$ & 27 & $-0.0467145 \pm 0.001164$ & $1.13123 \pm 0.013117$ & 0.983 \\
\hline $\begin{array}{l}\text { Limba/White afara } \\
\text { Terminalia superba }\end{array}$ & 35 & $-0.0480084 \pm 0.000790$ & $1.10629 \pm 0.011088$ & 0.991 \\
\hline $\begin{array}{l}\text { Samba/Obeche } \\
\text { Triplochiton scleroxylon }\end{array}$ & 19 & $-0.0539734 \pm 0.000976$ & $1.16087 \pm 0.012704$ & 0.994 \\
\hline
\end{tabular}

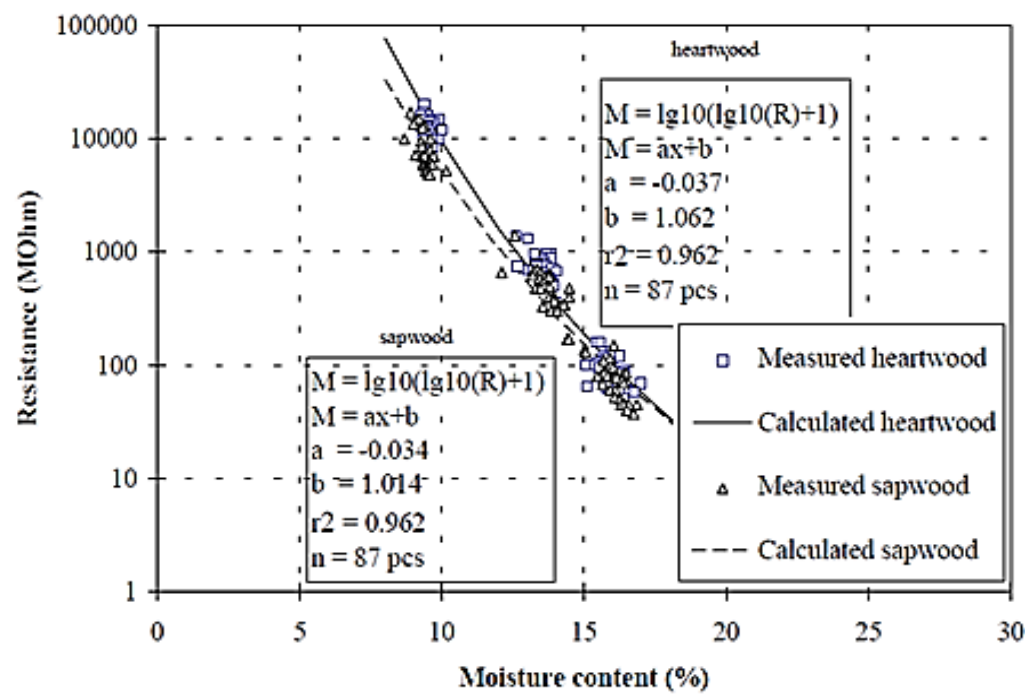

Figure 9. Electrical resistance values of sapwood and heartwood for Pine [12] 
Table 4. Calculated Moisture (a) and Resistance Values (b) for Pine Sapwood and Heartwood [12]

\begin{tabular}{|c|c|c|}
\hline Resistance & \multicolumn{2}{|c|}{ a) Moisture content, \% } \\
& Sapwood & Heartwood \\
\hline 10 MOhm & 21.0 & 20.6 \\
1000 MOhm & 12.1 & 12.4 \\
10000 MOhm & 9.3 & 9.8 \\
\hline Moisture & \multicolumn{2}{|c|}{ b) Resistance. MOhm } \\
content & Sap wood & Heart wood \\
\hline $8 \%$ & 33200 & 68300 \\
$12 \%$ & 1100 & 1400 \\
$16 \%$ & 90 & 90 \\
\hline
\end{tabular}

\section{Proposed Algorithm to Estimate the Leakage Current in Various Tree Species}

It is necessary to consider tree species, short-term environmental conditions (temperature and humidity) and long-term environmental conditions (seasonal variations) in leakage current calculations. To consider long-term environmental conditions in calculations, the tomography imagery of each season will be used. Using tomography imagery, the initial resistivity of tree in each season is obtained. This resistance is assigned to a specific environmental condition by which the initial moisture content of tree (MC0) is achieved. So for each season, there will be an initial resistivity at initial moisture content.

According to Eq 3, the electrical resistance can be calculated based on corresponding moisture content.

$$
\mathrm{R}=10^{\left(10^{a \cdot M C+b}-1\right)}
$$

Values of coefficients of relation 4 are selected according to studied species. According to constant dimensions of tree and based on $\mathrm{Eq} \mathrm{4,} \mathrm{tree} \mathrm{resistivity} \mathrm{is} \mathrm{proportional} \mathrm{to} \mathrm{tree} \mathrm{electrical}$ resistance.

$$
\rho \alpha R \propto 10^{\left(10^{a . M C+b}-1\right)}
$$

Regarding Eq 5 and initial resistivity derived from tomography images $\left(\rho_{1}\right)$ and according to moisture content of tree, resistivity value corresponding to specified environmental conditions is estimated using the following equation. This obtained resistivity is applied to finite element analysis as input data and the power loss of tree is calculated (Figure 10).

$$
\rho_{2}=\rho_{1}\left[\frac{\left.10^{\left(10^{a . M C} C_{2}+b\right.}-1\right)}{\left.10^{\left(10^{a . M C} C_{1}+b\right.}-1\right)}\right]
$$

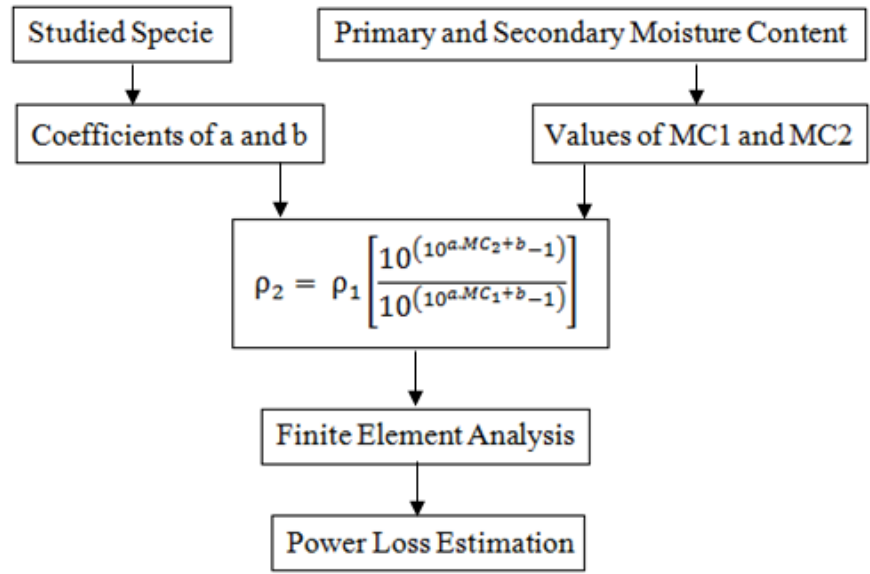

Figure 10. Flowchart of power losses estimation process 
For finite element analysis, tree trunk structure is assumed as two concentric truncated cones and boundary conditions are specified as voltage and current density of conductors and the ground voltage. From Maxwell's equation [14],

$$
\begin{aligned}
& \nabla \cdot E=-\nabla^{2} V+\mu \varepsilon \frac{\partial^{2} V}{\partial t^{2}} \\
& J=-\sigma E \\
& \nabla^{2} J-\mu \cdot \sigma \cdot \frac{\partial J}{\partial t}=0
\end{aligned}
$$

Where $\mu$ is the magnetic permeability, $\sigma$ is the electrical conductivity. Assuming sinusoidal excitation with an angular frequency $\omega$ and thus substituting

$$
\nabla \cdot E=-\nabla^{2} V+\mu \varepsilon \frac{\partial^{2} V}{\partial t^{2}}
$$

yields the $\mathrm{J}$-formulation in the frequency domain to solve eddy current problems:

$$
\nabla^{2} J-j . \omega . \mu . \sigma . J=0
$$

By employing the electric potential and considering the problem of three dimensions in Cartesian system of coordinates $(x, y, z)$, hence:

$$
\frac{\partial}{\partial x}\left(\frac{1}{\mu} \frac{\partial J}{\partial x}\right)+\frac{\partial}{\partial y}\left(\frac{1}{\mu} \frac{\partial J}{\partial y}\right)+\frac{\partial}{\partial z}\left(\frac{1}{\mu} \frac{\partial J}{\partial z}\right)-j . \omega \cdot \sigma . J=0
$$

The governing equation of each 4-node tetrahedron element is directly derived from the Maxwell's equations and solved using Galerkin approach [15].

\section{Power Loss Estimation of Cupressus Touching $20 \mathrm{kV}$ Power Line Based on the Proposed Algorithm}

A $20 \mathrm{kV}$ single core copper conductor XLPE insulated power cable has touched the power line and providing connection to tree (Figure 11). As minimum leakage current was in the millimeter regime, to accurately measure the total leakage flowing to the intended connection, current probe of power analyzer with resolution of $0.1 \mathrm{~mA}$ (Model Prova $6830 \mathrm{~A}+6801$ ) has been closed around the cable.

This experiment was done on live Cupressus Sempervirens tree grown next to $20 \mathrm{kV}$ feeder. Figure 12 shows the test procedure. Figure 13 displays the captured waveform of high impedance fault current on the scope. As shown in waveform hardcopy, the RMS value of current is 0.635 amps. This RMS value is related to environment with humidity of $65.5 \%$ and temperature of $28.5^{\circ} \mathrm{C}$. 


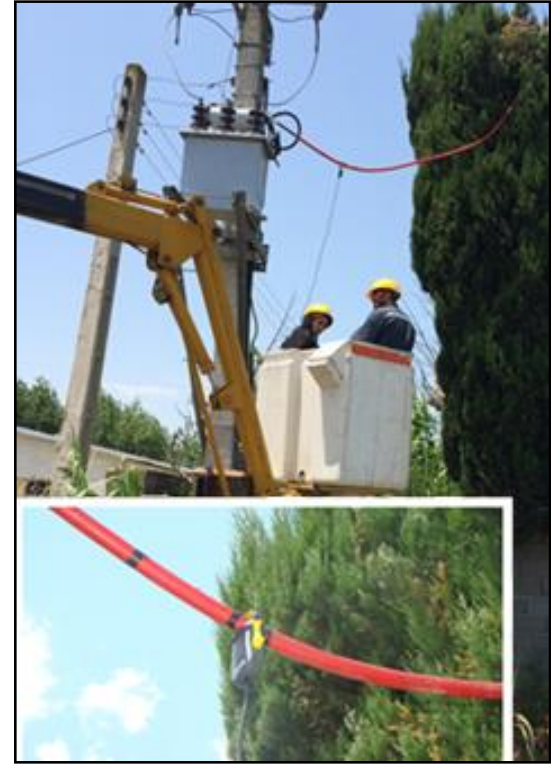

Figure 12. Implemented test procedure

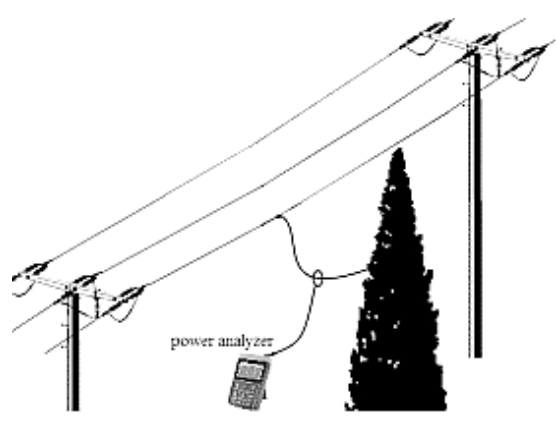

Figure 11. Test method on MV power distribution system

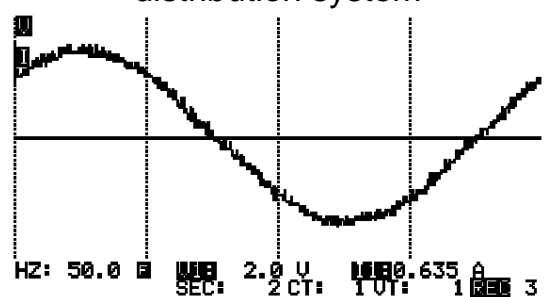

Figure 13. Captured waveform of high impedance fault current in tested Cupressus

Electrical properties of internal tissues of Cupressus Sempervirens trunk have been determined using tomographic cross section (Figure 14). The colors in the tomogram in Figure 14 represent the 2-dimensional distribution of electric resistivity in $\Omega \mathrm{m}$ where dark blue shows the lowest and dark red the highest measured electric resistivities. The $x$ - and $y$-axes of the tomogram indicate the dimension of the stem slice in meter.

To evaluate the performance of proposed algorithm, estimated leakage current values using algorithms were compared to the values obtained from experiments. According to Figure 14 , the amount of resistivity with corresponding moisture content of 11.1 percent is about 68 ohm meters. This resistivity was applied to FEM model as input data and leakage current and power loss value were obtained as output data. Figure 15 shows the estimated and measured value of electrical leakage current of Cupressus Sempervirens tree for FEM analysis.

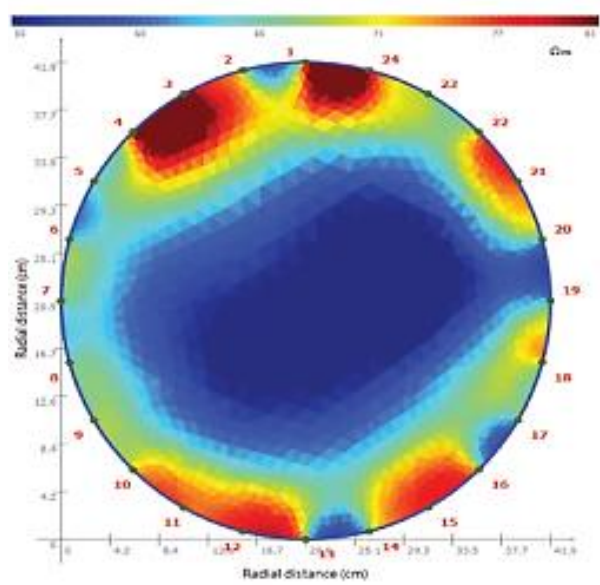

Figure. 14. Results of electrical resistivity tomography of Cupressus Sempervirens at moisture content of 11.1 percent $\left(17^{\circ} \mathrm{C}, 59 \%\right)$ [16] 


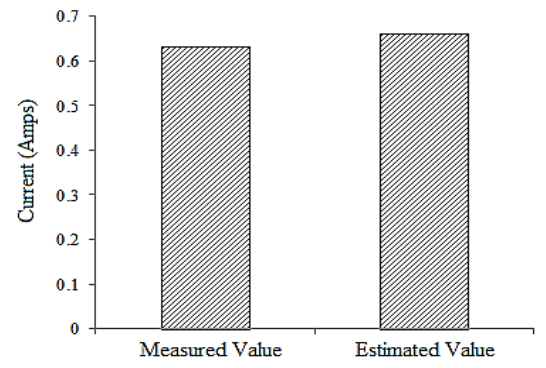

Figure 15. Leakage current through the Cupressus (Ampere) (tests conducted in the summer, $28.5^{\circ} \mathrm{C}, 65.5 \%$ )

The Figure 16 indicates the calculated value of tree power loss using finite element method for various combinations of relative humidity and temperature of spring. As shown in Figure 16, at higher levels of humidity, power loss rate is abruptly increased.

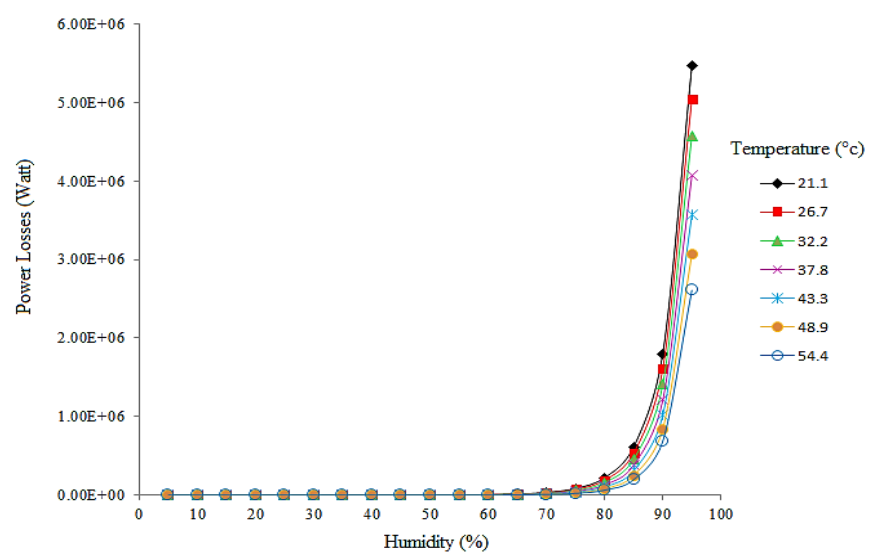

Figure 16. Power losses variations of cupressus touching MV power line under different environments of summer

8. Power Loss Estimation of Pine Touching $380 \mathrm{~V}$ Power Line Based on the Proposed Algorithm

To evaluate the performance of proposed algorithm, estimated leakage current values using algorithms were compared to the values obtained from experiments. According to Figure 17 , the amount of resistivity with corresponding moisture content of $6.8 \%$ is about $450 \mathrm{ohm}$.

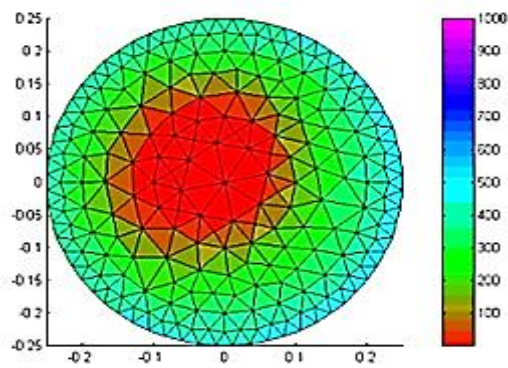

Figure. 17. Results of electrical tomography of Pine at moisture content of 6.8 percent in the spring [17] 
Figure 18 shows the estimated and measured value of electrical leakage current for FEM analysis. The difference between the measured and the estimated value of leakage current on Figure 18(a) and 18(b) is respectively about 2 and $24 \%$.

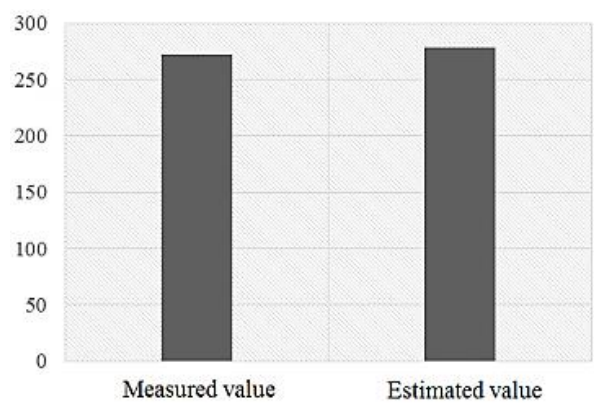

(a) spring, $19^{\circ} \mathrm{C}, 41 \%$

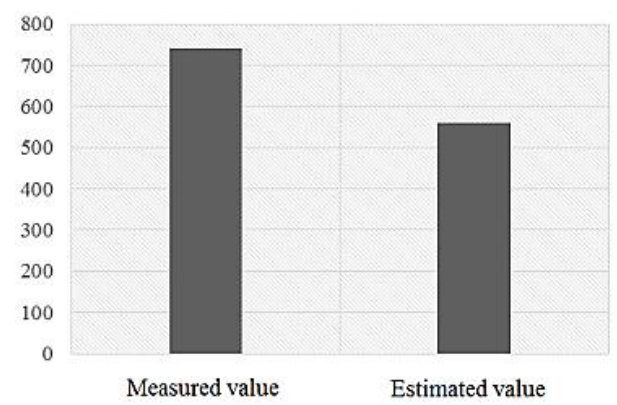

(b)spring, $19^{\circ} \mathrm{C}, 45 \%$

Figure 18. Leakage current through the Pine (Micro Ampere)

Figure 19 indicates tree power loss in Watts for various combinations of relative humidity and temperature of spring.

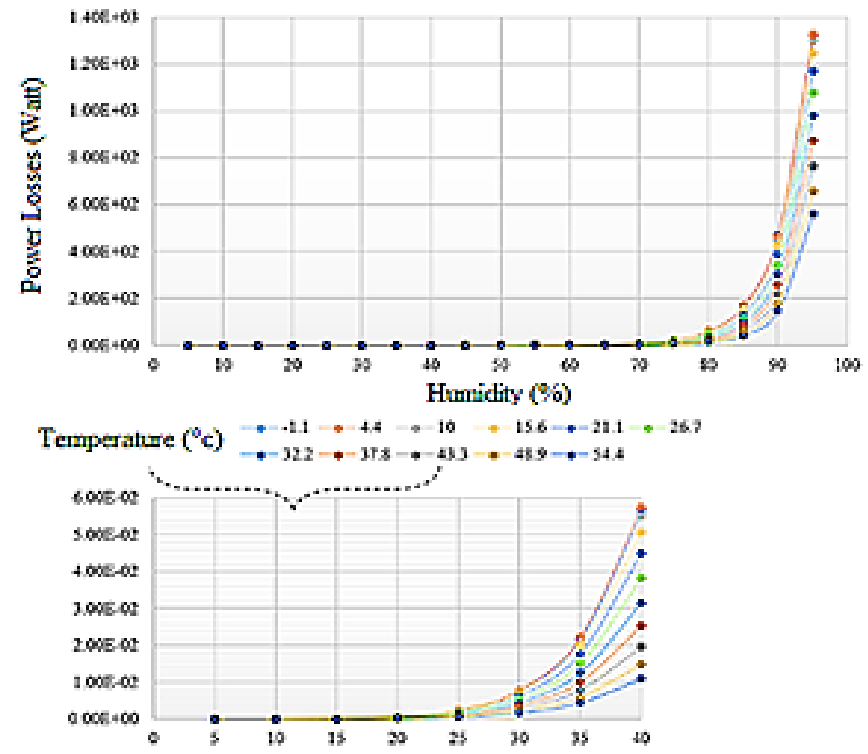

Figure 19. Power losses variations of pine under different environments of spring

\section{Conclusion}

One of the main problems with the vegetation-related power losses estimation, are impressibility of power losses from numerous factors. In this paper a new methodology for vegetation-related losses estimation in distribution systems was presented so as to reflect the impacts of all effective factors. The methodology used numerical techniques in order to approach accurate model for power losses. The results obtained from the proposed methodology were very close to those obtained from experiments. 


\section{Acknowledgement}

The author wishes to thank Electricity Distribution Company of Hamedan and Mazandaran for their participation in data collection.

\section{References}

[1] Santos WC, Lopes FV, Brito NSD, Souza BDe. High Impedance Fault Identification on Distribution Networks. IEEE Trans. Power Deliv. 2016: (99):1-1.

[2] Ghaderi A, Mohammadpour HA, Ginn H, Shin Y. High impedance fault detection in distribution network using time-frequency based algorithm. IEEE Trans. Power Deliv. 2014; 30: 1260-1268.

[3] Ghazizadeh-Ahsaee M. Accurate NHIF Locator Utilizing Two-End Unsynchronized Measurements. IEEE Trans. Power Deliv. 2013; 28: 419-426.

[4] Elkalashy NI, Lehtonen M, Darwish HA, Taalab AMI. Izzularab MA. DWT-Based Detection and Transient Power Direction-Based Location of High-Impedance Faults Due to Leaning Trees in Unearthed MV Networks. IEEE Trans. on Power Delivery. 2008; 23(1): 94-101.

[5] Pakonen P. Characteristics of partial discharges caused by trees in contact with covered conductor lines. IEEE Trans. Dielectr. Electr. Insul. 2008; 15(6): 1626-1633.

[6] Elkalashy NI, Lehtonen M, Darwish HA, Izzularab MA, Taalab AMI. Modeling and experimental verification of high impedance arcing fault in medium voltage networks. IEEE Trans. Dielectr. Electr. Insul. 2007; 14(2): 375-383.

[7] Hamzehbahmani H, Anderson P, Hall J, Fox D. Eddy Current Loss Estimation of Edge Burr-Affected Magnetic Laminations Based on Equivalent Electrical Network-Part I: Fundamental Concepts and FEM Modeling. IEEE Trans. Power Delivery. 2014; 29(2): 642-650.

[8] Reng X, Ding W, Zhou W, Fan C, and et al. The Moisture in SF Insulated CTs Considering Current and Change of Ambient Temperature. IEEE Trans. Power Delivery. 2014; 29(3): 1184-1191.

[9] Namdari F, Bahador N, Modeling trees internal tissue for estimating electrical leakage current. IEEE Trans. Dielectr. Electr. Insul. 2016; 23(3): 1663-1674.

[10] Simpson W, Tenwolde A. Physical properties and moisture relations of wood. In Wood handbookWood as an engineering material, Gen. Tech. Rep. FPL-GTR-113, Chapter 3, Madison, WI: U.S. Department of Agriculture, Forest Service, Forest Products Laboratory. 1999: 463.

[11] Hailwood AJ, Horrobin, S. Absorption of water by polymers: analysis in terms of a simple model. Trans. Faraday Soc. 1946; 42: 84-102.

[12] Forsén $H$, Tarvainen V. Accuracy and functionality of handheld wood moisture content meters. Finland: VTT Research Center, Espoo. 2000.

[13] Fernandez-Golfin J, and et al. Curves for the estimation of the moisture content of ten hardwoods by means of electrical resistance measurements. Forest Systems. 2012; 21(1): 121-127.

[14] Bargallo, R. Finite Elements for Electrical Engineering, EUETIB-UPC. 2006.

[15] Vázquez S, Barocio E, Jiménez Betancourt, R. A Crank-Nicolson Galerkin approach to the analysis of electromechanical oscillations in stressed power systems. Electric Power Systems Research. 2012; 86: 158-169.

[16] Lin CJ, Chung CH, Yang TH, Lin FC. Detection of electric resistivity tomography and evaluation of the sapwood-heartwood demarcation in three Asia Gymnosperm species. Silva Fennica. 2012; 46(3): 415-424.

[17] Sambuelli L, Socco LV, Godio A. Ultrasonic, electric and radar measurements for living trees assessment. Bollettino di Geofisica Teorica ed Applicata. 2003; 44(3); 253-279. 